\title{
А.Н. Лихолетов
}

ГОО ВПО «Донецкий национальный медицинский университет имени М. Горького», Донецк

\section{КЛИНИЧЕСКИЙ СЛУЧАЙ ХИРУРГИЧЕСКОГО ЛЕЧЕНИЯ ПЕРЕЛОМА ПАЛАЧА ІІІ ТИПА}

Травматический листез С2 позвонка (перелом палача) относится к тяжелой травме позвоночника. В структуре повреждений шейного отдела переломы палача составляют от 4 до 15\% [1-3].

Основным механизмом возникновения данного вида повреждений является гиперэкстензия, при котором происходит растяжение передней продольной связки, сближение задних полуколец С2 и С3 позвонков, перелом в области корней дужек. Продолжающаяся флексионная нагрузка ведет к смещению и запрокидыванию С2 позвонка кпереди. Величина смещения C2 относительно C3 позвонка зависит от степени разрушения передней, задней продольных связок и диско-связочного аппарата $[1,4]$. Для данного вида травмы характерна выраженная нестабильность, обусловленная повреждением как передних (дисколигаментарного комплекса), так и задних опорных структур позвоночника[5]. В настоящее время наибольшее распространение получила классификация повреждений данной области Effendi et al.[6], по которой переломы разделены на три типа: первый - стабильные переломы, при которых не возникает грубой деформации на уровне C2-C3 сегмента; второй - повреждения со значительной угловой деформацией (больше 11 градусов) или сдвиговой (больше 3,5 мм), что указывает на повреждение мягкотканных структур и всего дискосвязочного комплекса; третий - переломовывих дужки С2, с травмированием не только передних, но и задних связочных структур; кроме того, имеется сцепившийся вывих сломанной дужки C2. Levine и Edwards [7] ввели в классификацию Effendi дополнительный второй тип А переломов, при котором наряду с переломом дужки имеется повреждение диска с разрывом задней продольной связки на уровне С2-C3. При этом авторы утверждают, что при повреждении II и III типа нельзя осуществлять тракцию грузом более 5 кг из-за опасности повреждения спинного мозга.

Минимальная неврологическая симптоматика в виде болевого синдрома с ограничени- ем подвижности верхнешейного отдела позвоночника обусловлена расширением размеров позвоночного канала в сагиттальной плоскости на уровне повреждения $[1,4,8]$. Однако при значительном смещении существует высокая вероятность развития грубой неврологической симптоматики. Так, отмечено до 57\% случаев, когда наблюдаются тетрапарез, витальные нарушения, что обусловлено сдавлением или ушибом спинного мозга, повреждением вертебральных артерий в отверстиях поперечных отростков С2 позвонка [1, 9].

Данные обстоятельства обусловливают необходимость проведения надежной стабилизации, способы которой в настоящее время окончательно не определены. Одни хирурги отдают предпочтение консервативным методам лечения с фиксацией шейного отдела гало-аппаратом [10], другие - различным хирургическим вариантам передней или задней инструментальной стабилизации $[5,2,11,12]$. При консервативном лечении нестабильных переломов чаще отмечаются неудовлетворительные результаты, при том что при наличии сращения переломов в последующем появляются кифоз и нестабильность на уровне C2-C3 [11, 13].

Наиболее распространены задние методы трансартикулярная и транспедикулярная фиксации $[11,14,15]$, которые требуют определенного хирургического опыта: имеется опасность повреждения спинного мозга или позвоночной артерии [16], при переломах дужки С2 не всегда возможно установить транспедикулярные шурупы с двух сторон и нет возможности воздействовать на поврежденный межпозвонковый диск $[11,17,18]$.

Целью данной работы явилось описание успешного результата лечения методом передней стабилизации у пациента с переломом палача III типа по Levine и Edwards на примере собственного клинического наблюдения.

(c) А.Н. Лихолетов, 2020

(c) Университетская Клиника, 2020 

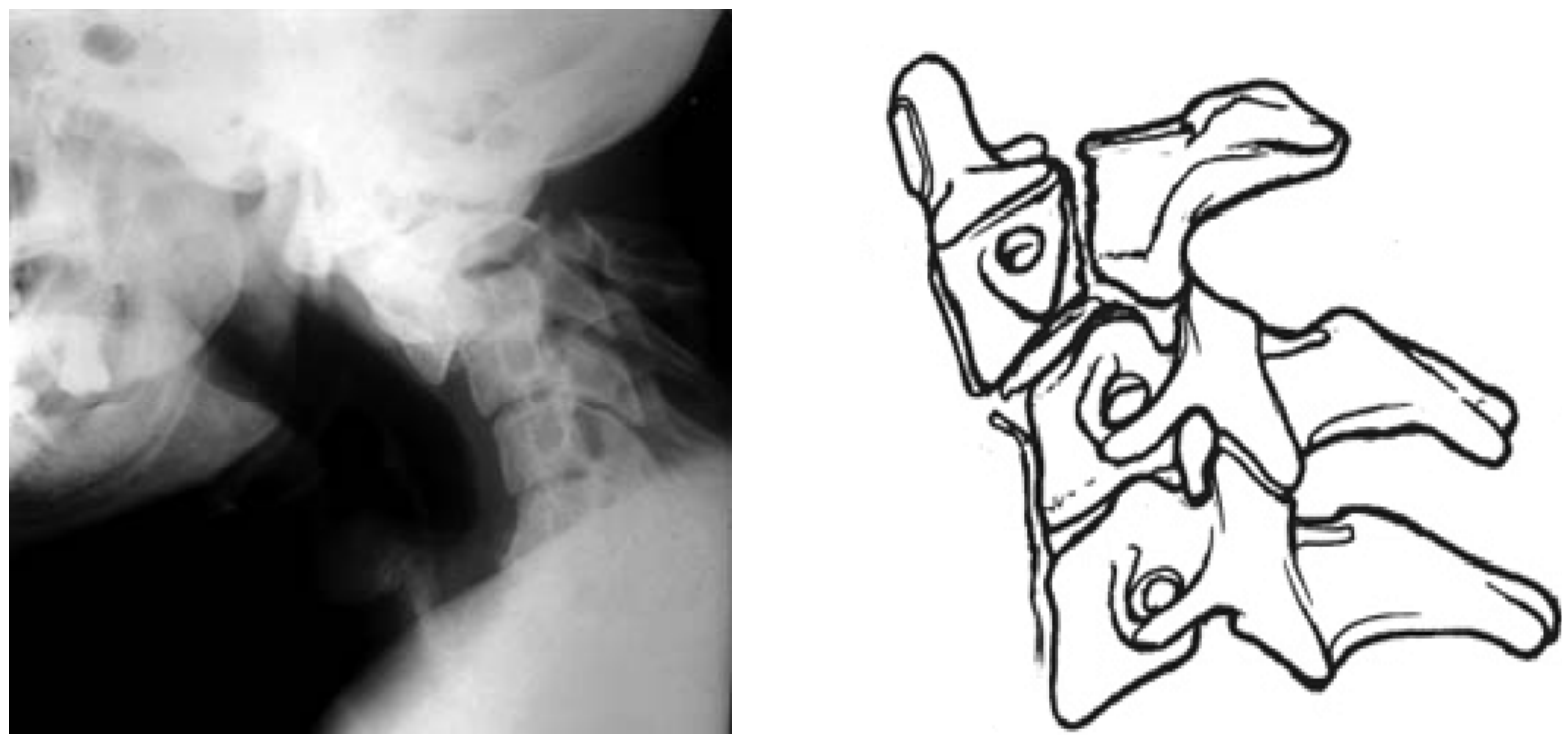

Рис. 1. Больной С., 33 лет. Фотоотпечатки с рентгенограммы в боковой проекции при поступлении и схема повреждения. Определяется смещение кпереди С2 позвонка, повреждение межпозвонкового диска С2-С3, вывих в дугоотросчатых суставах и перелом дужки С2 позвонка.
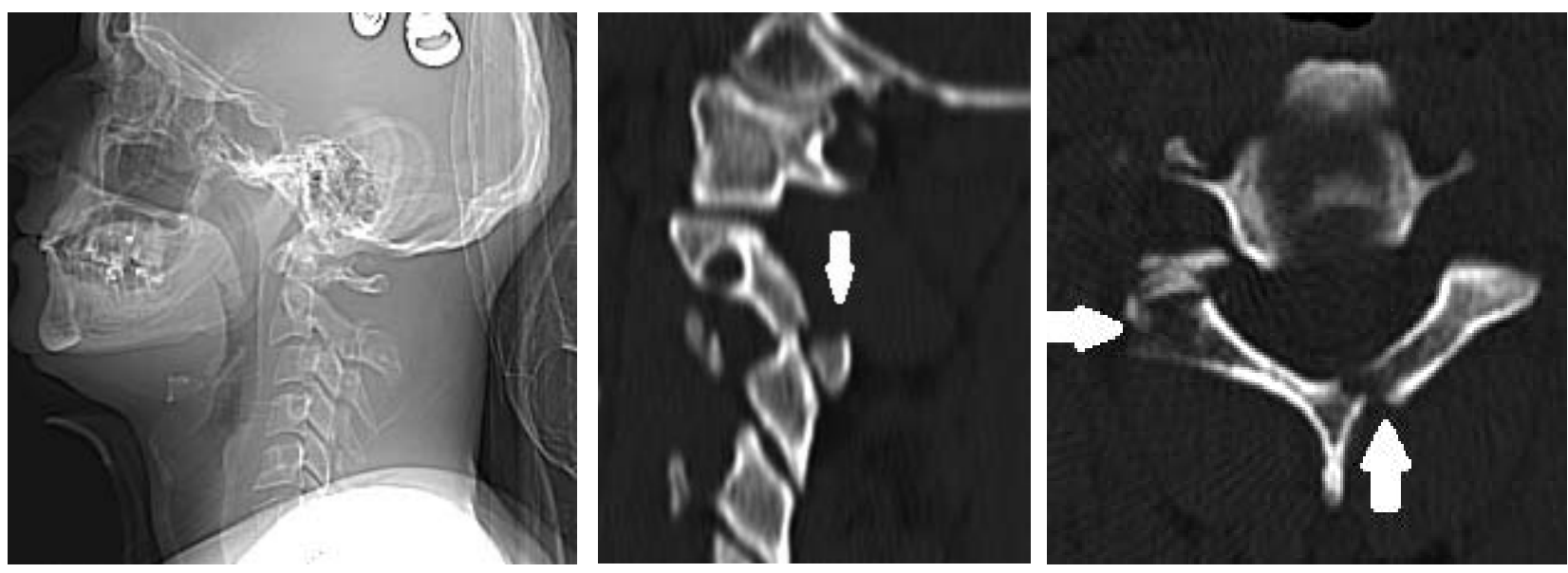

Рис. 2. Больной С., 33 лет. Фотоотпечатки с СКТ-томограмм. Определяется система скелетного вытяжения, уменьшение смещения С2 позвонка кпереди до 1/2 поперечника, соскальзывание его устранено, переломовывих дугоотросчатого сустава C2-C3, нарушение конгруэнтности в суставе C2-C3 слева, перелом дужки С2 позвонка и основания остистого отростка.

Пациент С., 33 лет, история болезни № 16352 , поступил в приемное отделение Республиканского травматологического центра г. Донецка 14.07.2019 г. с диагнозом: Переломовывих С2 позвонка кпереди, перелом дужек и суставных отростков С2-С3 позвонков, с выраженным болевым и корешковым синдромом.

Со слов больного, травму получил в быту, в результате обрушения металлической конструкции 14.07.2019 г. Доставлен в РТЦ родственниками на легковом автомобиле, без иммобилизации. Осмотрен нейрохирургом, травматологом, анестезиологом, выполнены рентгенограммы шейного отдела позвоночника. Госпитализиро- ван в ургентном порядке для дообследования и определения тактики лечения.

При поступлении: общее состояние тяжелое. В неврологическом статусе: сознание ясное, 15 баллов по ШКГ. Менингеальных знаков нет. Глазные щели равны. Зрачки правильной формы, среднего размера, равны. Фотореакция симметричная, сохранена. Движения глазных яблок в полном объеме. Лицо симметрично. Язык по средней линии, глотание и фонация не нарушены. Движения в конечностях не ограничены. Сухожильные живые, слева с рук снижены. Гипестезия в зоне иннервации C3 и С4 корешков слева. Функция тазовых органов произвольная. Шейный отдел позвоночника иммобилизи- 


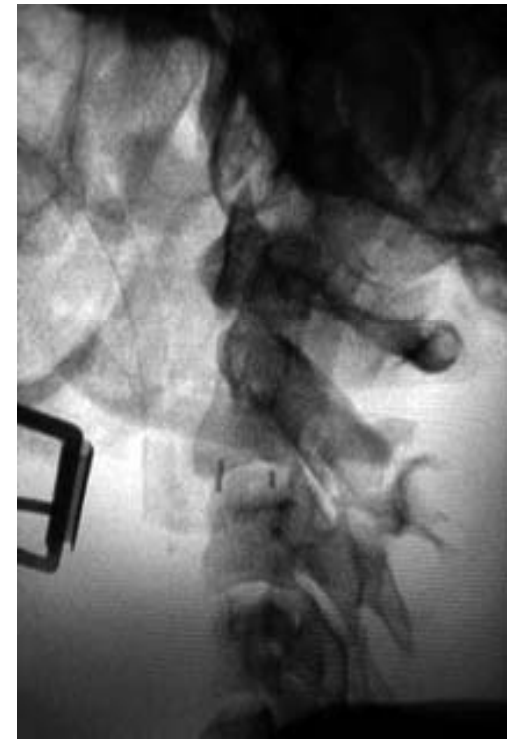

a

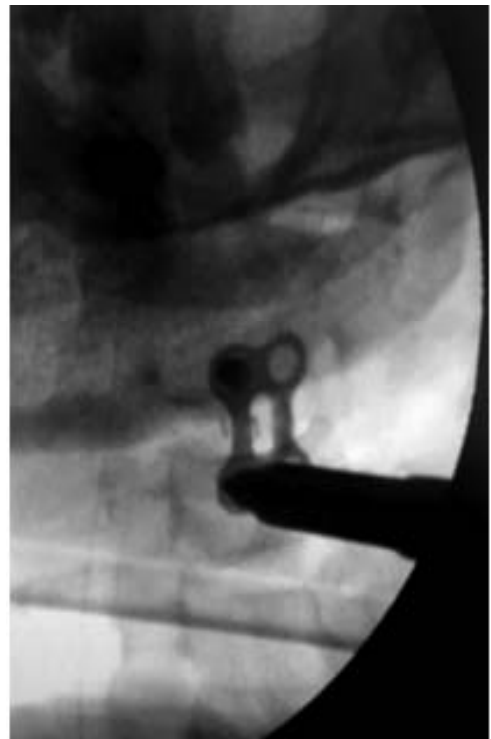

б

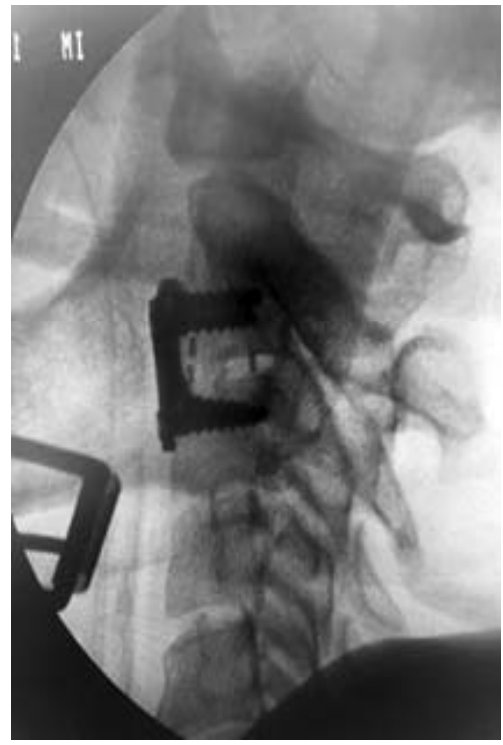

B

Рис. 3. Радиологический контроль во время операции. а) Радиологический контроль после вправления вывиха С2 позвонка и установки межтелового импланта из РЕЕК-пластика. Ось позвоночника восстановлена. б) Радиологический контроль в прямой проекции во время остеосинтеза С2-С3 металлической пластиной. в) Радиологический контроль в боковой проекции во время остеосинтеза С2-С3 металлической пластиной.

рован воротником Шанца. Местно: резко выраженная болезненность при пальпации остистых отростков С2-С6 позвонков, напряжение мышц на этом уровне. Вынужденное положение головы в согнутом положении и поворотом вправо. По 10-балльной визуально-аналоговой шкале (ВАШ) уровень болевого синдрома расценен на 9/10.

На рентгенограммах отмечен переломовывих C2 позвонка кпереди более чем на $1 / 2$ поперечника, перелом дужки и дугоотросчатых суставов С2-С3 (рис. 1.).

Больной госпитализирован в реанимационное отделение, где уложен в функциональном положении, произведено наложение системы скелетного вытяжения за теменные бугры весом 5 кг.

Диагноз уточнен при проведении спиральной компьютерной томографии (СКТ) от 15.07.2017 г.: определяется уменьшение смещения С2 позвонка кпереди до $1 / 3$ поперечника, соскальзывание его устранено, переломовывих дугоотросчатого сустава C2-C3, нарушение конгруэнтности в суставе С2-С3 слева, перелом дужки С2 позвонка и основания остистого отростка, перелом дужки С3 позвонка - без смещения (рис. 2.). По классификации Levine и Edwards данное повреждение относится к типу III.

По поводу выявленной патологии в плановом порядке выполнено оперативное вмешательство 22.07.2019 г.: открытое вправление переломовывиха С2 позвонка, передняя дискэктомия C2-C3, межтеловой корпородез кейджем из
РЕЕК-пластика с аутокостью, передний спондилосинтез металлической пластиной С2-C3.

Описание операции. Оперативное пособие выполнено под эндотрахеальным комбинированным многокомпонентным наркозом с искусственной вентиляцией легких, в положении на спине. Подчелюстным доступом произведен доступ к телам С2 и С3 позвонков и скелетированы передние поверхности тел позвонков, после чего обнаружено снижение межпозвонкового промежутка, множественные кровоизлияния в переднюю продольную связку с разрывами ее, повреждение с кровоизлияниями межпозвонкового диска С2-С3. При этом отмечено, что тело C2 позвонка выстоит кпереди. Произведена дискэктомия С2-C3 с резекцией задней продольной связки, которая также была с кровоизлияниями и разрывами, после чего зачищены замыкательные пластинки смежных тел позвонков кюреткой. При помощи петли Глиссона произведена тракция по оси позвоночника с вправлением вывиха С2 позвонка. В межпозвонковый промежуток подобран, а затем установлен кейдж из РЕЕК-пластика высотой 6 мм, наполненный аутокостью, взятой из остеофитов передненижнего края тела С2 позвонка, после чего уложена и установлена титановая пластина на переднюю поверхность тел С2-С3 позвонков под радиологическим контролем (рис. 3.), которая фиксирована двумя парами шурупов. Гемостаз производился по ходу операции. Послойное ушивание раны, асептическая повязка. Осложнений и кровопотери во время операции не было. 

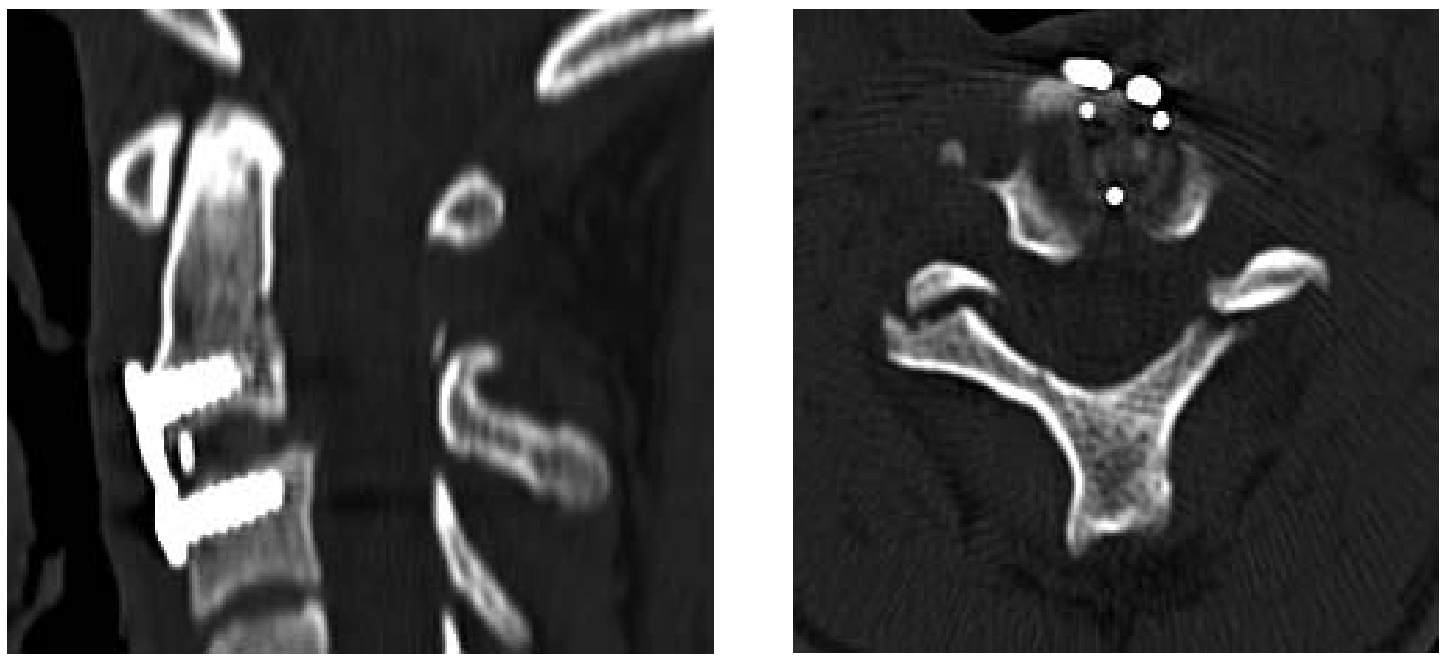

Рис. 4. СКТ-контроль после операции. Смещение тела С2 позвонка устранено. Ось позвоночника восстановлена. Положение металлоконструкции и межтелового импланта удовлетворительное.
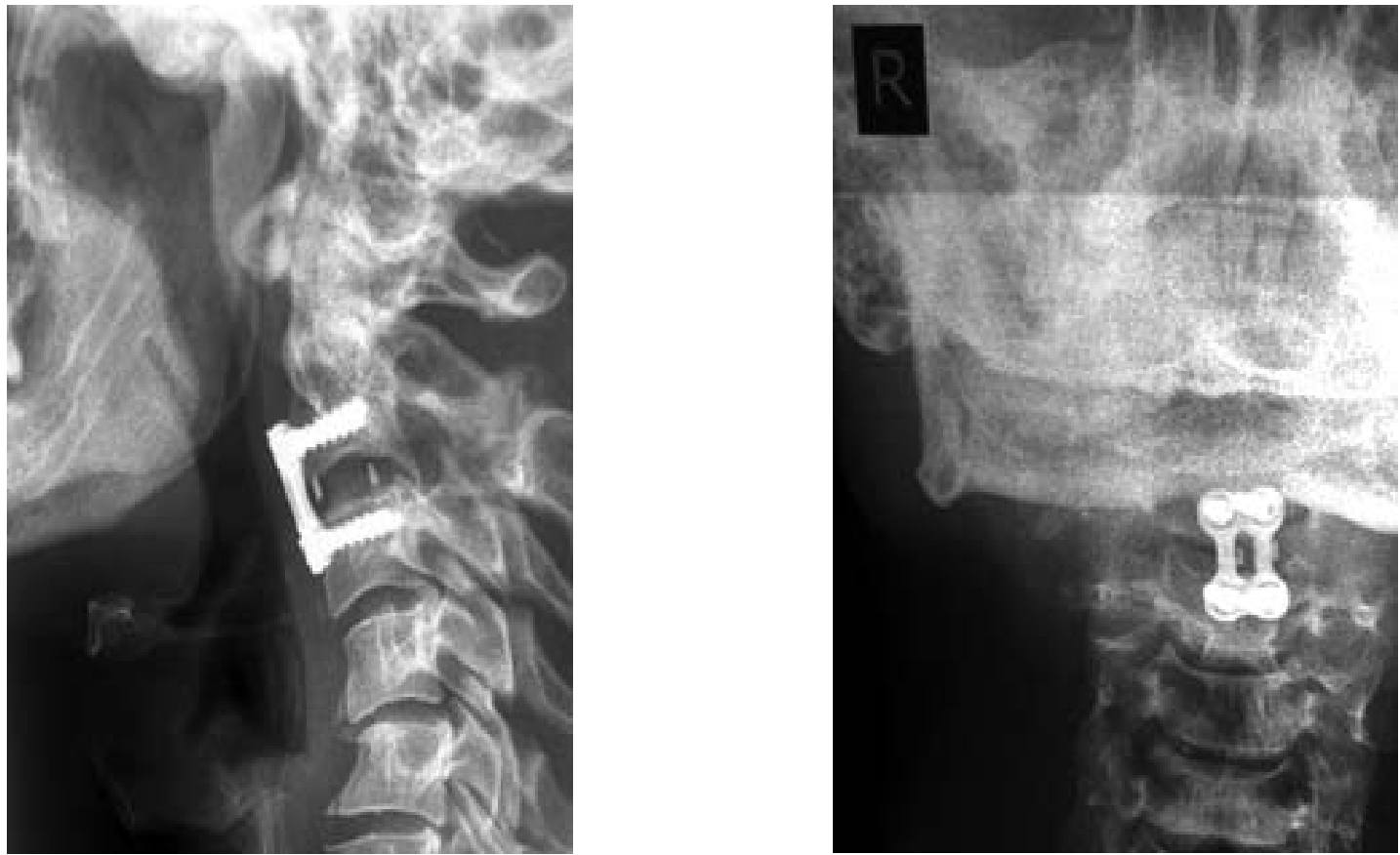

Рис. 5. Рентген-контроль через 6 месяцев после операции. Положение имплантируемой конструкции удовлетворительное.

Больной вертикализирован на вторые сутки после удаления дренажей в жестком шейном ортезе. Отмечается значительное уменьшение болевого (ВАШ 0-1/10) и корешкового синдрома.

На контрольном СКТ-исследовании после операции (рис. 4.) стояние металлоконструкции и кейджа корректное, ось позвоночного столба восстановлена в полной мере, компрессия образований позвоночного канала устранена. Больной в стационаре получил стандартную терапию в послеоперационном периоде и выписан через 12 дней после операции под наблюдение врача по месту жительства в удовлетворительном состоянии.

Пациенту через 6 месяцев произведен радиологический контроль в двух проекциях (рис. 5.), на котором изменения положения имплантируемой конструкции не обнаружено.

Через год после проведенного оперативного лечения на СКТ-контроле четко прослеживается сформированный спондилодез, сращение поврежденных структур заднего опорного комплекса С2 и С3 позвонков в правильном соотно- 

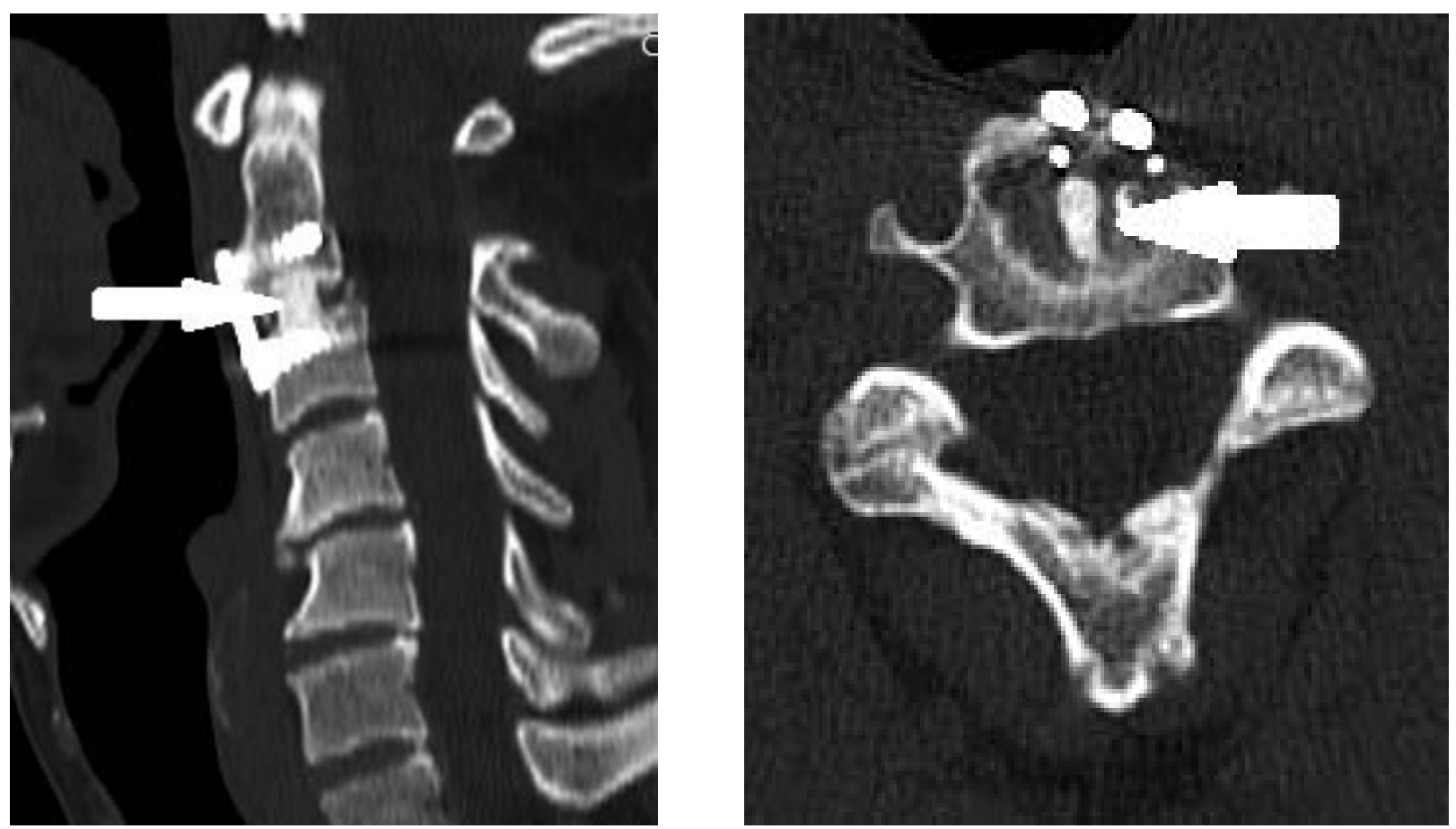

Рис. 6. СКТ-контроль через год после операции. Сформированный костный блок (состоявшийся спондилодез указан стрелкой) - на уровне С2-С3 Положение металлоконструкции и межтелового импланта удовлетворительное.

шении (рис. 6.). Пациент не испытывает болевых ощущений, корешковая симптоматика отсутствует, в социальном плане - адаптирован в полном объеме.

Лечение переломов палача II-III типа остается спорным в выборе способа лечения. Одни авторы предлагают начинать с консервативных методов лечения, другие предпочитают оперативные. Наибольшее распространение получили методы задней фиксации, которые позволяют добиться надежной стабильности в ходе операции, но эти методики не исключают возникновения опасных осложнений и не воздействуют на травмированный диск, трудны в исполнении и требуют определенного хирургического опыта. Особый интерес приведенного клинического случая вызывает лечение перелома дужки С2 с одновременным переломовывихом в суставе C2-C3 (III тип, по классификации Effendi, Levine и Edwards). Нам удалась ранняя закрытая репозиция у пациента методом скелетного вытяжения за теменные бугры, восстановление оси позвоночника, декомпрессия нервнососудистых образований позвоночного канала, а затем надежная стабилизация передним доступом. В процессе наблюдения за пациентом в течение года - сформирован надежный спондилодез, удалось добиться положительного рентгенологического и клинического результата.

\section{В Ы В 0 д Ы}

Определение тактики лечения повреждений верхнешейного отдела позвоночника должно производиться дифференцированно, после детального выполнения всего комплекса диагностических мероприятий. Для точного определения характера поражения позвоночника и спинного мозга пострадавшим с травмой шейной локализации, помимо стандартной рентгенографии, необходимо выполнять СКТ-исследование, что позволяет получить более полные сведения о локализации костных отломков, повреждении межпозвонковых дисков, степени стеноза позвоночного канала. Лечебная тактика при переломе палача заключается в восстановлении нормальных топографо-анатомических соотношений между позвоночником и спинным мозгом. Выбор оперативного лечения в представленном случае был индивидуальным и последовательным, определялся характером и особенностями повреждения позвоночника: потребовалось выполнение скелетного вытяжения за теменные бугры, восстановление оси позвоночника, а затем стабилизация передним доступом. Своевременное и качественное проведенное оперативное лечение у пострадавшего с переломом палача III типа, адекватно избранное для этого вида повреждения, обеспечило благоприятный исход в ближайшем и отдаленном периодах. 


\section{А.Н. Лихолетов}

ГОО ВПО Донецкий национальный медицинский университет им. М. Горького, г. Донецзк

\section{КЛИНИЧЕСКИЙ СЛУЧАЙ ХИРУРГИЧЕСКОГО ЛЕЧЕНИЯ ПЕРЕЛОМА ПАЛАЧА ІІІ ТИПА}

В статье приведен литературный обзор и описан успешный результат лечения методом стабилизации позвоночника передним доступом с предварительным скелетным вытяжением за теменные бугры у пациента с нестабильным травматическим листезом С2 позвонка (перелом палача) III типа, по классификации Effendi, Levine и Edwards. Для точного определения характера травмы костных и мягкотканных структур позвоночника и спинного мозга, помимо стандартной рентгенографии, было проведено СКТ- исследование, что позволило получить полные сведения о локализации костных отломков и повреждении межпозвонкового диска. Оперативная комбинированная тактика лечения в представленном случае являлась индивидуальной, что позволило обеспечить благоприятный исход в ближайшем и отдаленном периодах.

Ключевые слова: травматический листез С2 позвонка, перелом палача, межтеловой спондилодез.

\section{A.N. Likholetov}

\section{SEI HPE «M. Gorky Donetsk National Medical University», Donetsk}

\section{CLINICAL CASE OF SURGICAL TREATMENT OF TYPE III HANGMAN'S FRACTURE}

The article provides a literature review and describes the successful result of treatment by anterior approach to spine stabilization with preliminary skeletal extension behind the parietal tubercles in a patient with unstable traumatic C2 vertebra listhesis (hangman's fracture) type III according to the classification of Effendi, Levine and Edwards. In order to accurately determine the nature of trauma to the bone and soft tissue structures of the spine and spinal cord, in addition to standard radiography, a CT study was conducted, which allowed us to obtain complete information about the localization of bone fragments and damage to the intervertebral disc. The operative combined treatment strategy in the presented case was individual, which allowed to ensure a favorable outcome in the near and long-term periods.

Key words: traumatic C2 vertebra listhesis, hangman's fracture, interbody fusion.

\section{ЛИТЕРАТУРА}

1. Некрасов М.А., Некрасов А.К.,. Крылов В.В, Гринь А.А. Лечение больных с травматическим спондилолистезом С2 позвонка. Нейрохирургия. 2005; 2: 20-26.

2. Губин А.В., Бурцев А.В., Рябых С.О. Задняя фиксация переломов палача. Хирургия позвоночника. 2014; 4 : 15-19.

3. Triggs KJ, Ballock RT, Lee TQ, et al. The effect of angled insertion on halo pin fixation. Spine. 1989; 14: 781-783.

4. Луцик А.А., Раткин И.К., Никитин М.Н. Краниовертебральные повреждения и заболевания. Новосибирск, 1998. 557.

5. Duggal N., Chamberlain R.H., Perez-Garza L.E. et al. Hangman's fracture: a biomechanical comparison of stabilization techniques. Spine. 2007; 32: 182-187.

6. Effendi B., Roy D., Cornish B. et al.. J. Bone Joint Surg. Br. 1981; 63: 319-327.

7. Levine A.M., Edwards C.C. The management of traumatic spondylolisthesis of the axis. J. Bone JointSurg. Am. 1985; 67: 217-226.

8. Полищук Н.Е., Корж В.Я., Фищенко В.Я. Повреждения позвоночника и спинного мозга. Киев, 2001. 388.

9. Marotta T.R., White L., Ter Brugge K.G. et al. An unusual type of hangman's fracture. Neurosurgery. 1990; 26: 848851.

10. Vaccaro A.R., Madigan L., Bauerle W.B. et al. Early halo immobilization of displaced traumatic spondylolisthesis of the axis. Spine. 2002; 27: 2229-2233.

11. Рерих В.В., Жеребцов С.В. Хирургическое лечение повреждений С2. Хирургия позвоночника. 2004; 3: 20-25.

12. Boos N., Aebi M. Spinal Disorders: Fundamentals of Diagnosis and Treatment. Springer; 2008. 1165.

\section{REFERENCES}

1. Nekrasov M.A., Nekrasov A.K.,. Krylov V.V, Grin’ A.A. Lechenie bol'nykh s travmaticheskim spondilolistezom S2 pozvonka. Neirokhirurgiya. 2005; 2: 20-26 (in Russian).

2. Gubin A.V., Burtsev A.V., Ryabykh S.O. Zadnyaya fiksatsiya perelomov palacha. Khirurgiya pozvonochnika. 2014; 4: 15-19 (in Russian).

3. Triggs KJ, Ballock RT, Lee TQ, et al. The effect of angled insertion on halo pin fixation. Spine. 1989; 14: 781-783.

4. Lutsik A.A., Ratkin I.K., Nikitin M.N. Kraniovertebral'nye povrezhdeniya i zabolevaniya. Novosibirsk, 1998. 557 (in Russian).

5. Duggal N., Chamberlain R.H., Perez-Garza L.E. et al. Hangman's fracture: a biomechanical comparison of stabilization techniques. Spine. 2007; 32: 182-187.

6. Effendi B., Roy D., Cornish B. et al.. J. Bone Joint Surg. Br. 1981; 63: 319-327.

7. Levine A.M., Edwards C.C. The management of traumatic spondylolisthesis of the axis. J. Bone JointSurg. Am. 1985; 67: 217-226.

8. Polishchuk N.E., Korzh V.Ya., Fishchenko V.Ya. Povrezhdeniya pozvonochnika i spinnogo mozga. Kiev, 2001. 388 (in Russian).

9. Marotta T.R., White L., Ter Brugge K.G. et al. An unusual type of hangman's fracture. Neurosurgery. 1990; 26: 848851.

10. Vaccaro A.R., Madigan L., Bauerle W.B. et al. Early halo immobilization of displaced traumatic spondylolisthesis of the axis. Spine. 2002; 27: 2229-2233.

11. Rerikh V.V., Zherebtsov S.V. Khirurgicheskoe lechenie povrezhdenii S2. Khirurgiya pozvonochnika. 2004; 3: 2025 (in Russian). 
13. Mangione P., Courant C., Vital J.-M. et al. Fractures des pedicules de 1'axis: a propos d'une serie homogende 100 cas. Rachis. 1990; 5: 375-383.

14. Бурцев А.В., Губин А.В. Выбор метода стабилизации при травмах шейного отдела позвоночника. Гений ортопедии. 2017; 23; 2: 140-146. doi: 10.18019/10284427-2017-23-2-140-146.

15. Resnick Daniel K., Lapsiwala Samir, Trost Gregory R. Anatomic suitability of the C1-C2 complex for pedicle screw fixation. Spine. 2002; 27: 1494-1498.

16. Masashi Neo, Mutsumi Matsushita, Yasushi Iwashita et al. Atlantoaxial transarticular screw fixation for a highriding vertebral artery. Spine. 2003; 28 (7): 666-670.

17. Resnick Daniel K., Lapsiwala Samir, Trost Gregory R. Anatomic suitability of the C1-C2 complex for pedicle screw fixation. Spine. 2002; 27: 1494-1498.

18. Herkowitz H.N. The Spine. 6th Edition. Elsevier Saunders. 2011; 2020.
12. Boos N., Aebi M. Spinal Disorders: Fundamentals of Diagnosis and Treatment. Springer; 2008. 1165.

13. Mangione P., Courant C., Vital J.-M. et al. Fractures des pedicules de 1'axis: a propos d'une serie homogende 100 cas. Rachis. 1990; 5: 375-383.

14. Burtsev A.V., Gubin A.V. Vybor metoda stabilizatsii pri travmakh sheinogo otdela pozvonochnika. Genii ortopedii. 2017; 23; 2: 140-146. doi: 10.18019/1028-4427-201723-2-140-146 (in Russian).

15. Resnick Daniel K., Lapsiwala Samir, Trost Gregory R. Anatomic suitability of the C1-C2 complex for pedicle screw fixation. Spine. 2002; 27: 1494-1498.

16. Masashi Neo, Mutsumi Matsushita, Yasushi Iwashita et al. Atlantoaxial transarticular screw fixation for a highriding vertebral artery. Spine. 2003; 28 (7): 666-670.

17. Resnick Daniel K., Lapsiwala Samir, Trost Gregory R. Anatomic suitability of the C1-C2 complex for pedicle screw fixation. Spine. 2002; 27: 1494-1498.

18. Herkowitz H.N. The Spine. 6th Edition. Elsevier Saunders. $2011 ; 2020$. 